\title{
Affectivity of biological cement's application to sandy soil for geotechnical engineering
}

\author{
Hung Wen $\mathrm{Yi}^{1}$, Emma Yuliani ${ }^{2}$, Maytri Handayani ${ }^{1, a}$, Hsu Chia Sseng ${ }^{1}$ and Chen Ssu Ching ${ }^{3}$ \\ ${ }^{1}$ Dept. of Civil Engineering, National Central University, Taiwan \\ ${ }^{2}$ Dept. of Water Resources Engineering, Brawijaya University, Indonesia \\ ${ }^{3}$ Dept. of Life Science, National Central University, Taiwan
}

\begin{abstract}
In this research, the authors analyze the addition of bacterial producer of biological cement on sandy soil to increase its stability. Pseudomonas $s p$ was injected into the soil to produce urease enzyme, which converts urea that reacted with water become ammonium and carbonate, causing calcite precipitation. Soil stability can be improved by the production of pore-filling materials and particle-binding materials through the calcite precipitation process. The aim of these applications is to improve the mechanical properties of soil that it will be more suitable for construction or environmental purposes. After bacterial inoculation, the experiment with variation of bacterial content concluded the best way to increase soil stability is inject $15 \%$ bacteria relative to total weight of soil. Highest permeability reduction is $73,73 \%$ and highest shear strength increation for cohesion is 6,84 with friction angle $44,46^{\circ}$. California Bearing Ratio test with 10 of hits generated that the treatment soil can proved a significant penetration stress changed. From Environmental Scanning Electron Microscopy test results of the inoculation sand test images and surface scan, the formed exopolysaccharide attached to the wall of the sand soil particles which expected will fill, patch, and close the pores between the sandy soil particles.
\end{abstract}

\section{Introduction}

In choosing the type of soil for materials of retaining construction such as river embankments or earth dams, the permeability is an important characteristic to consider in addition to the compaction characteristics. A soil shear strength value is required to calculate the soil bearing capacity or to calculate the earth pressure force on the retaining walls.

To increase soil stability, efforts to reduce the permeability and increase the shear strength is very important way because it can run on all types of foundations that consist of one or more types of rock. The last few years have been done a lot of research and studies about how to improve the stability of the soil. One of the most exciting research is soil stability improvement by adding bacteria that producing "biological cement" (exopolysaccharide) into the soil. This research has been tested in several countries, but is limited to a few types of soil material just in those countries.

\footnotetext{
${ }^{a}$ Corresponding author : hmaytri@gmail.com

(C) The Authors, published by EDP Sciences. This is an open access article distributed under the terms of the Creative Commons Attribution License 4.0 (http://creativecommons.org/licenses/by/4.0/).
} 
If the general material used for material reduction in permeability and increased shear strength is chemicals, but in this study the authors will try to analyze the addition of bacterial producing exopolysaccharide in sandy soil as an alternative to the material. Exopolysaccharides have been defined as organic polymers of microbial origin, which in biofilm systems, are frequently responsible for binding cells and other particulate materials to each others and to the substrate [1].

In the process of bacteria inoculation in the soil, there will be three processes. They are bioclogging process where bacteria will produce a material that is capable of filling the pores of the soil to reduce tha value of permeability, biocementation process where bacteria produces a material that is able to increase the shear strength of the soil, and the process of gas production through bacterial activity which can lower the risk of liquefaction in sandy soil [2].

A frequent problem encountered in the repair of the foundation is to overcome seepage discharge and the value of cohesion that has not been controlled. In this case that can be cultivated is to reduce seepage discharge and the cohesion values until it reaches a certain threshold then conduct maintenance, inspection regularly, and improvements as necessary.

A decrease in the permeability of the chemicals used to hold seepage in rocks that are not too impermeable and temporary (approximately one year) although there is also an age more than 30 years (semi-permanent). A decrease in the permeability of these chemicals only used when the usual way cannot be used, because it is relatively more expensive and the process must be carried out carefully because it can damage human skin.

Given these problems, the author tries to give a solution in the form of an initial step the latest innovations in geotechnical engineering. This innovation is expected to be environmentally friendly, do not damage human skin, is also quite effective to reduce permeability and increase soil shear strength material, especially of sandy material.

To test the effectiveness of this study, the sand samples will be tested permeability with constant head test, shear strength with direct shear test, compaction with California Bearing Ratio test, and ESEM (Environmental Scanning Electron Microscopy) test.

\section{Literature review}

Bacterial that suitable for making biogrouting is non-pathogenic and environmentally friendly. Moreover, unlike the use of cement, soil or contaminated soil can be treated or improved even without disturbing the soil itself or the surrounding environment, it is because bacterial can penetrate and reproduce themselves in the soil. Many types of bacteria can be used for biogrouting, including Pseudomonas sp.

A genus of motile, polar-flagellate, non-spore forming, strictly aerobic bacteria (family Pseudomonadaceae) containing straight or curved, but not helical, gram-negative rods that occur singly. Most species are saprophytic. Saprophytes are characterized by the use of a certain type of digestive mechanism, called an extra-cellular digestion. This process involves the secretion of digestive substances into the surrounding environment, where they break down organic matter into simple substances. The resulting nutrients are then absorbed directly through the cell membrane of the organism, and metabolized. The metabolism is respiratory, never fermentative. They occur commonly in soil and fresh water and marine environments.

For this research, the authors use constant-head test to determination of hydraulic conductivity. In this laboratory setup, the water supply at the inlet is adjusted in such a way that the difference of head between the inlet and the outlet remains constant during the test period. After a constant flow rate is established, water is collected in a graduated flask for a known duration.

The total volume of water collected (where $\mathrm{Q}=$ volume of water collected, $\mathrm{A}=$ area of cross section of the soil specimen, $\mathrm{t}=$ duration of water collection) may be expressed as:

$$
Q=A v t=A(k i) t
$$


and because

$$
i=\frac{h}{L}
$$

Eq. (2) can be substituted into Eq. (1) to yield

$$
Q=A\left(k \frac{h}{L}\right) t \text { or } k=\frac{Q L}{A h t}
$$

The direct shear is the oldest and simplest form of shear test arrangement. The test equipment consist of a metal shear box in which the soil specimen is placed. Normal force on the specimen is applied from the top of the shear box. For most soil mechanics problems, it is sufficient to approximate the shear stress on the failure plane as a linear function of the normal stress (Coulomb, 1776). This linear function (where $c=$ cohesion, $\sigma=$ normal stress on the failure plane, $\varnothing=$ angle of internal friction, $\tau_{f}=$ shear strength) can be written as:

$$
\tau_{f}=c+\sigma \tan \emptyset
$$

The CBR value is then defined as the ratio of the measured force to that required for similar penetration into a standard sample of crushed California limestone rock. The only calculation necessary is to express the measured force for a certain penetration as a percentage of the 'standard' force for the same penetration. In equation below, $\mathrm{F}$ is the measured force and $\mathrm{Fs}$ is the force required (standard force).

$$
\mathrm{CBR}=(\mathrm{F} / \mathrm{Fs}) \times 100 \%
$$

SEM analysis is a test used to display the scanned electrons of a solid object. SEM Test using a high-energy electron beam to generate a signal different from the surface of an object. In the SEM test the output is produced is the magnification image of the electron signal generation, so there is a difference between objects of different material because of the different electron arrangements. Terms and provisions for SEM test is specified in ASTM E-986-97.

\section{Research methodology}

In probability theory and statistics, variance is the expectation of the squared deviation of a random variable from its mean. Informally, it measures how far a set of (random) numbers are spread out from their average value.

Researchers did the experiment with the variations of curing days, relative density, and nutrients type. The curing days in this experiments divided by two different types that 7 days and 28 days. The environment condition is outside building (with real conditions according to the site, temperature follows the existing conditions, exposed by sunshine and humidity). For the variation of relative density, researchers divided by two types, i.e. relative density $50 \%$ and relative density $70 \%$. Researchers locked the relative density to uniform the sample also know the comparison and effectiveness from both relative density. For the type of nutrient, researchers also divided by two types, nutrient type 1 and nutrient type 2. Nutrient Type 1 consist of $\mathrm{CaCl}_{2}, \mathrm{MgSO}_{4}, \mathrm{~K}_{2} \mathrm{HPO}_{4}$, and Saccharose [3]. Meanwhile, Nutrient type 2 consist of LB Broth Powder, Urea, $\mathrm{CaCl}_{2}, \mathrm{NH}_{4} \mathrm{Cl}$, $\mathrm{NaHCO}_{3}$, Saccharose. 


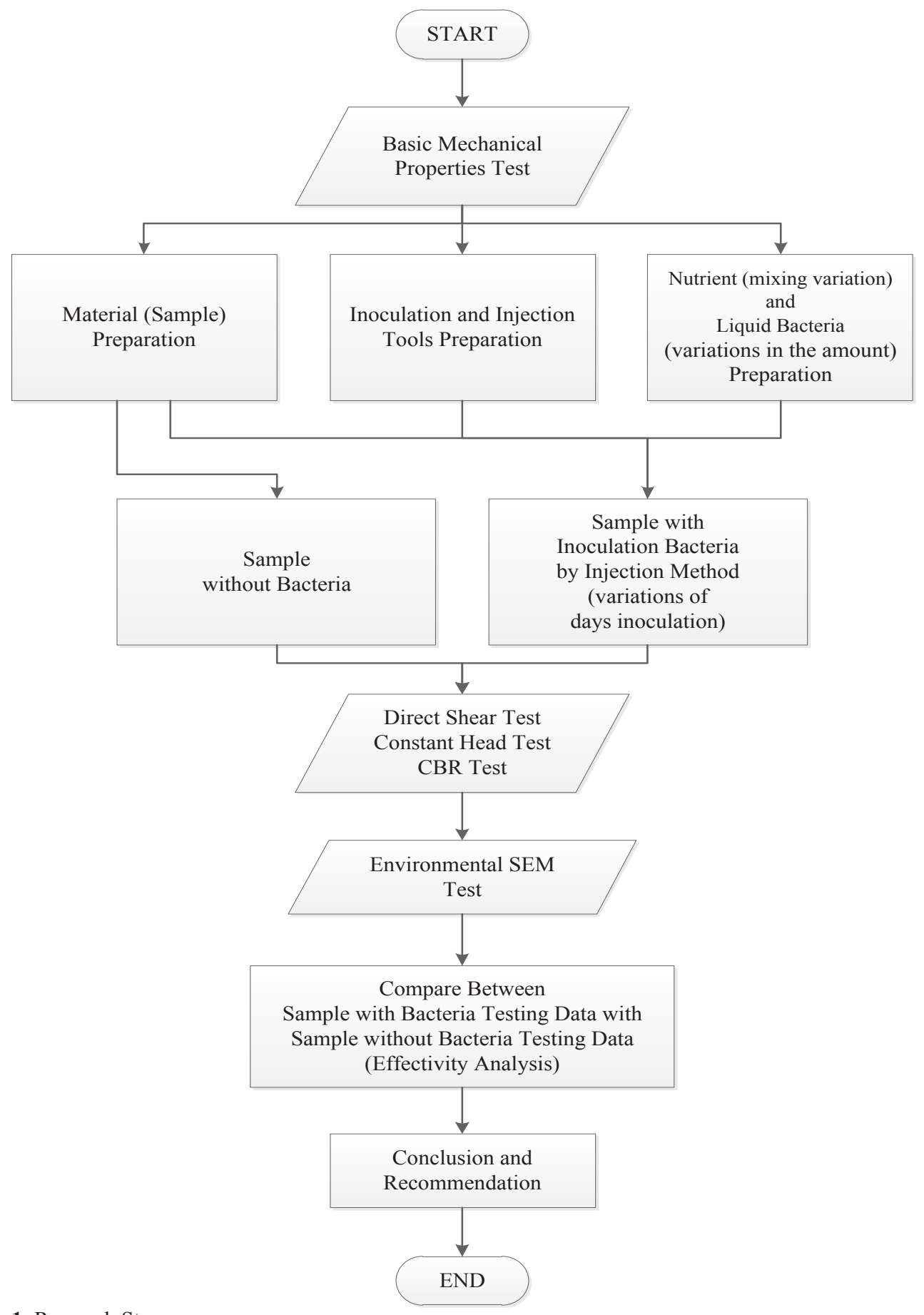

Figure 1. Research Stage 


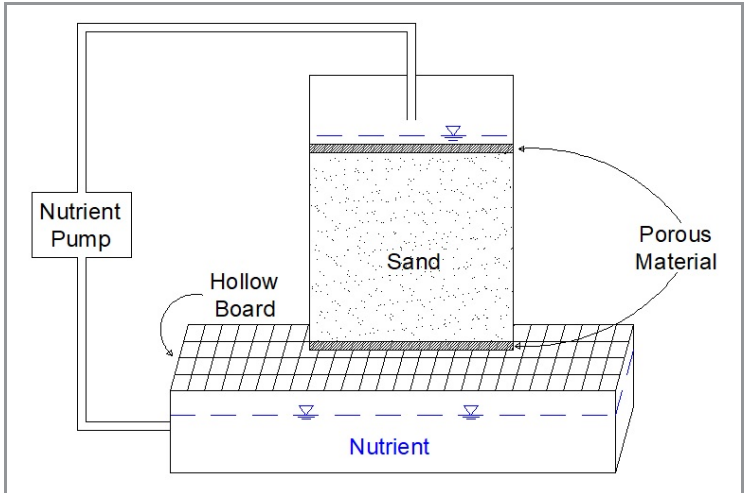

Figure 2. Research Methodology

Table 1. Fundamental Characteristic of Sandy Soil used in the tests

\begin{tabular}{|c|c|}
\hline Sandy Soil Type & Silica Sand \\
\hline Specific gravity, Gs & 2.65 \\
\hline $\mathrm{D}_{60}(\mathrm{~mm})$ & 0.208 \\
\hline $\mathrm{D}_{30}(\mathrm{~mm})$ & 0.176 \\
\hline $\mathrm{D}_{10}(\mathrm{~mm})$ & 0.155 \\
\hline Coefficient of uniformity, $\mathrm{C}_{\mathrm{u}}$ & 1.344 \\
\hline Coefficient of curvature, $\mathrm{C}_{\mathrm{c}}$ & 0.963 \\
\hline$\gamma_{\mathrm{dmax}}\left(\mathrm{kN} / \mathrm{m}^{3}\right)$ & 16.285 \\
\hline$\gamma_{\text {dmin }}\left(\mathrm{kN} / \mathrm{m}^{3}\right)$ & 13.830 \\
\hline Unified Soil Classification System & $\mathrm{SP}$ \\
\hline
\end{tabular}

\section{Results and discussions}

During inoculation, the microbacterials produced the synthesis exopolysaccharide different composition of chemical and physical properties. This exopolysaccharide production is affected by the growth phase and the development of microbacterial, nutrients available in its development media, also $\mathrm{pH}$ and temperature. This synthesis process is the process by which it is formed polymers and peptidoglycan on microbacterial cell walls. Unity the polymers and the peptidoglycan are then referred to as exopolysaccharide. Exopolysaccharides, which are secreted by communal microbacterials in the sample, can clog and glue the structure samples through the pores of the sand grains.

In the process of inoculation of microbacterials in the sand soil, it will there are 3 processes (Ivanov V and Chu J. 2008 [2]):

1. There is a bioclogging process that is the process by which microbacteria will producing both the material and the mass of the microbacterial cell itself which is capable of filling the interstellar cavities of the sand-soil can reduce porosity and sand permeability rate.

2. There is a biocementation process that is the process by which microbacteria produce a slime material extracellular polysaccharide able to increase the shear strength and stiffness of the sand soil.

3. There is a process that produces biogas which is the process where generated bubbles (air) through which microbacterial activity can be reduce the risk of liquefaction potential of sand soil.

The accumulation of cell mass that occurs in microbacteria, slime and gas produced microbacteria located on the sand soil will make the sand soil more impermeable to water [2]. This happens because extracellular polysaccharides produced by microbacteria will alter arrangement of sand structures. Production of these extracellular polysaccharides will bind the sand soil particles and fill the intercavities sand grains. 
Based on Figure 3. located on the next page, it can be seen that in the process of biocementation material produced by microbacteria will bind the sand soil particles so that the sand soil become more dense and the ability to withstand the shear force will increased. Besides, the bioclogging process occurs clogging or blockage by material produced by microbacteria or by microbacterial activity that clogs or fills cavities between particles soil so that it can inhibit the flow of water as it passes through the particles sand soil and decrease the permeability of the sand soil.
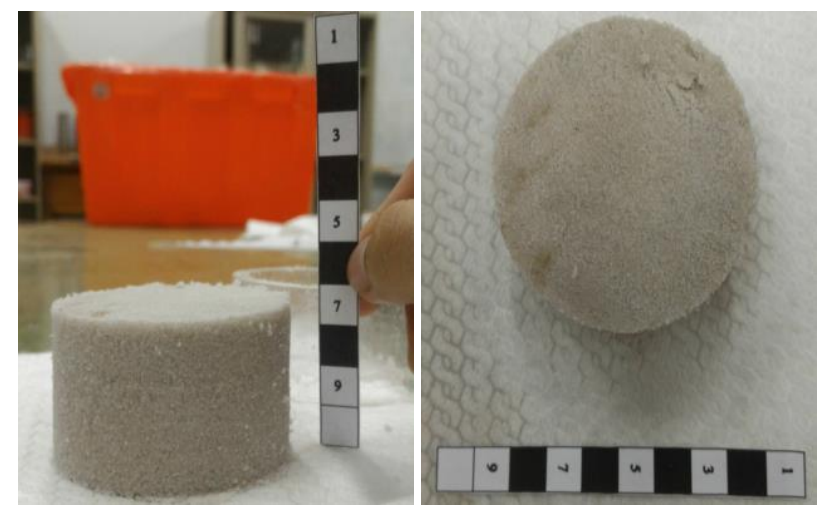

Figure 3. Sandy soil direct shear sample inoculated with Pseudomonas sp

In general, factors affecting extracellular production polysaccharide produced by microbacteria is growth medium, condition environment, and the formation of side reactions. Medium used to produce polysaccharide compounds usually contain carbon elements which is used to limit the comparison of nutrients with elements nitrogen. The change of $60-80 \%$ from the complex carbon source used into a simple polymer compound (hydrolysis) obtained high results from the fermentation process of the polysaccharide compound. An important step in the growth of microorganisms and the formation of products is the formulation of the medium the good one. Good growth and production medium should contain carbon, nitrogen, phosphorus, sulfur, potassium, and magnesium salts (Chawla et al. 2009 [4]). Besides, according to DeJong et al. 2006 [5], microorganisms are often lies in the cementation of sediments containing calcium, magnesium, iron, manganese and aluminum in the form of crystalline carbonates, silica, phosphates, sulfides and hydroxides, especially iron hydroxide.

In this research media used in the form of sugar (saccharose) and mineral salts, which are $\mathrm{CaCl}_{2}$, $\mathrm{MgSO}_{4}, \mathrm{~K}_{2} \mathrm{HPO}_{4}$, and Saccharose. The carbon element which is required in the extracellular production process of the polysaccharide is obtained of saccharose $\left(\mathrm{C}_{11} \mathrm{H}_{22} \mathrm{O}_{11}\right)$. The required salts are potassium obtained of $\mathrm{K}_{2} \mathrm{HPO}_{4}$, magnesium is obtained from $\mathrm{MgSO}_{4}$, Calcium is obtained from $\mathrm{CaCl}_{2}$. Calcium $(\mathrm{Ca})$ serves as a precipitation in calcite formation which will be influential in the bioclogging process or impairment permeability. Magnesium $(\mathrm{Mg})$ functions in anaerobic fermentation play a role in biocementation. In addition, there are also Nitrogen (N2) substances obtained from the sample soil element.

Urease positive bacteria are commonly used for the biogrouting method and they are able to hydrolyse urea into ammonium and carbonate. The ammonium will increases the $\mathrm{pH}$ value, initiating the precipitation of calcium carbonate $\left(\mathrm{CaCO}_{3}\right)$ [6], which acts as a binding bridge between the sand particles. $\mathrm{CaCO}_{3}$ precipitation occurs at the bacterial cell surface if there are sufficient concentration of $\mathrm{Ca}^{2+}$ and $\mathrm{CO}_{3}{ }^{2-}$ in solution [7].

$$
\begin{aligned}
\mathrm{CO}\left(\mathrm{NH}_{2}\right)_{2}+2 \mathrm{H}_{2} \mathrm{O} & \rightarrow 2 \mathrm{NH}_{4}^{+}+\mathrm{CO}_{3}^{2-} \\
\mathrm{Ca}^{2+}+\mathrm{CO}_{3}{ }^{2-} & \rightarrow \mathrm{CaCO}_{3}(\mathrm{~s})
\end{aligned}
$$

Compared with chemical or cement injection methods that are potentially damaging to the environment, MICP has been proposed as an environmentally friendly technique ([2, 8]), whereby the soil body can be treated in situ. Biogrouting technology can be used for applications such as 
increasing the stiffness and strength of sand $([9,10])$ and rocks to enhance slope stability and foundation bearing capacity, reducing foundation settlements, mitigating the liquefaction potential of saturated sand [5], reducing the hydraulic conductivity of dykes and dams by bioclogging, preventing soil erosion, reducing infiltration from ponds or to construction [2], strengthening of concrete and remediation of cracks [11].

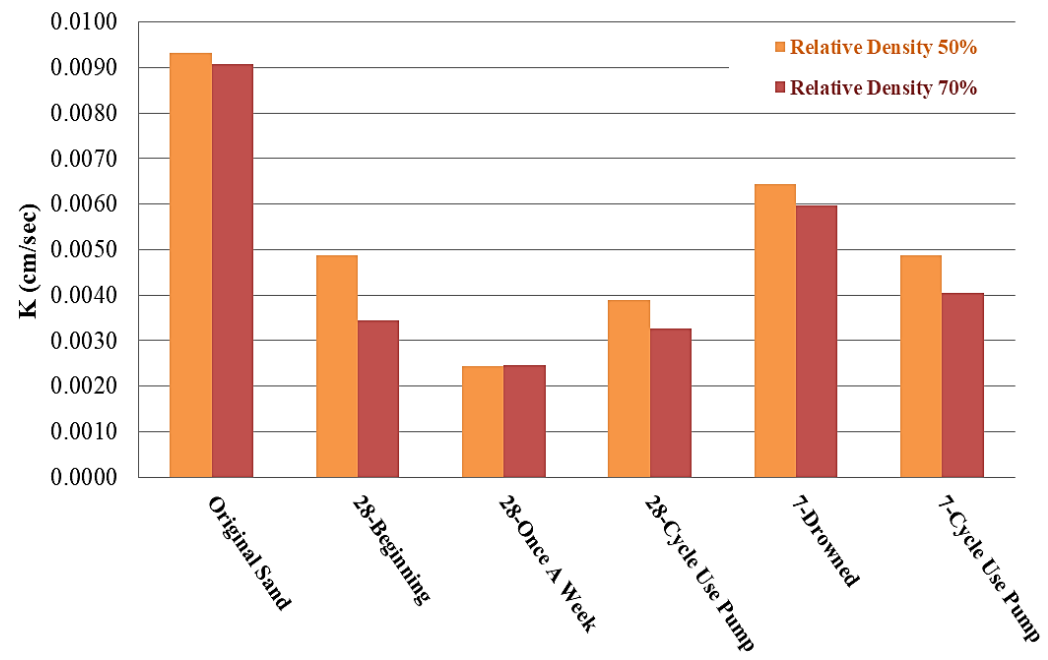

Figure 4. Chart of Constant Head Permeability Test Result

Table 2. Result Recapitulation of Direct Shear Strength Test

\begin{tabular}{|c|c|c|c|c|c|c|}
\hline \multirow{4}{*}{$\begin{array}{c}\text { Treatments of } \\
\text { Sample }\end{array}$} & \multicolumn{3}{|c|}{$\mathrm{Dr}=70 \%$} & \multicolumn{3}{|c|}{ Dr $=50 \%$} \\
\hline & \multirow{2}{*}{ Cohesion } & \multirow{2}{*}{$\begin{array}{c}\text { Friction } \\
\text { Angle }\end{array}$} & \multirow{2}{*}{\begin{tabular}{|c|} 
Shear \\
Strength \\
\end{tabular}} & \multirow{2}{*}{ Cohesion } & \multirow{2}{*}{$\begin{array}{c}\text { Friction } \\
\text { Angle }\end{array}$} & \multirow{2}{*}{\begin{tabular}{|c|} 
Shear \\
Strength
\end{tabular}} \\
\hline & & & & & & \\
\hline & $(\mathrm{kPa})$ & (Degrees) & $(\mathrm{kPa})$ & $(\mathrm{kPa})$ & (Degrees) & $(\mathrm{kPa})$ \\
\hline Original Sand & 3.82 & 38.22 & 36.61 & 4.28 & 35.94 & 34.47 \\
\hline 28-Beginning & 5.03 & 34.02 & 33.13 & 5.07 & 34.27 & 33.44 \\
\hline 28-Once A Week & 7.28 & 35.95 & 37.47 & 6.05 & 33.53 & 33.64 \\
\hline 7-Drowned & 0.23 & 39.52 & 34.58 & 2.54 & 36.87 & 33.77 \\
\hline 7-Cycle Use Pump & 7.11 & 41.67 & 44.17 & 6.84 & 44.46 & 47.70 \\
\hline
\end{tabular}

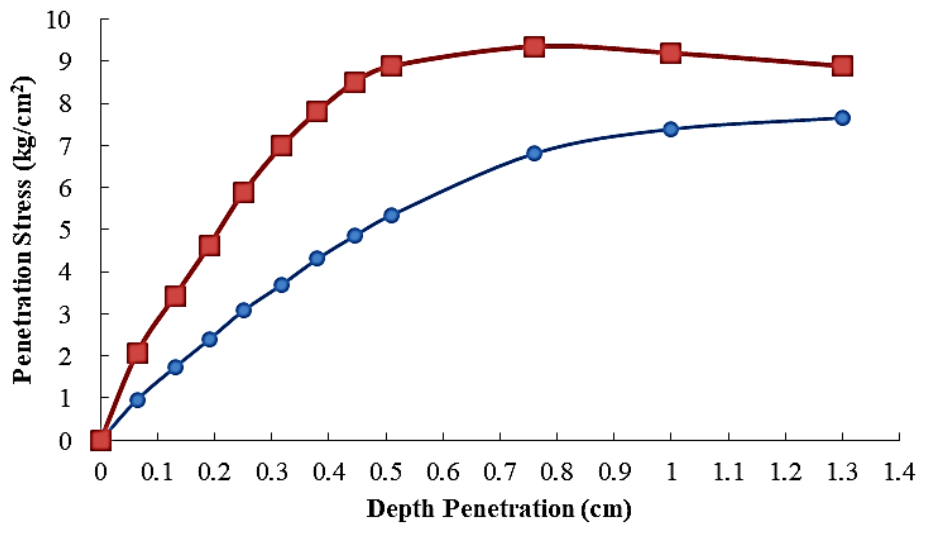

$\rightarrow-$ Original Soil $\rightarrow-$ Treatment Soil

Figure 5. CBR Result with 10 Number of Hits 

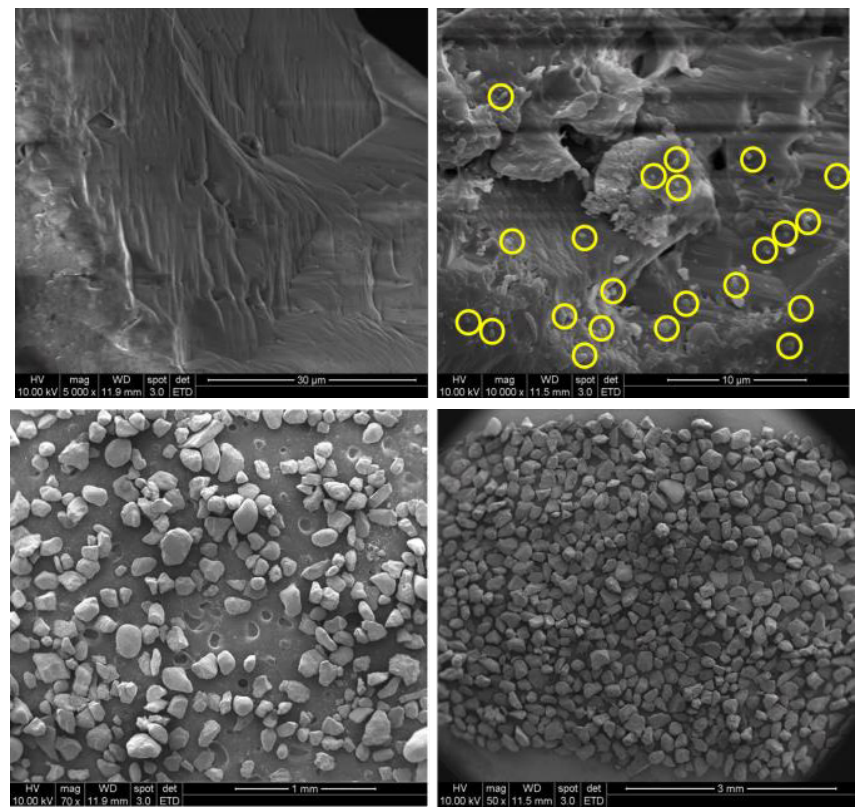

Figure 6. Comparison ESEM Test Result of Original Sand (left) with SEM Test Result of Sand inoculated with Pseudomonas sp. (right)
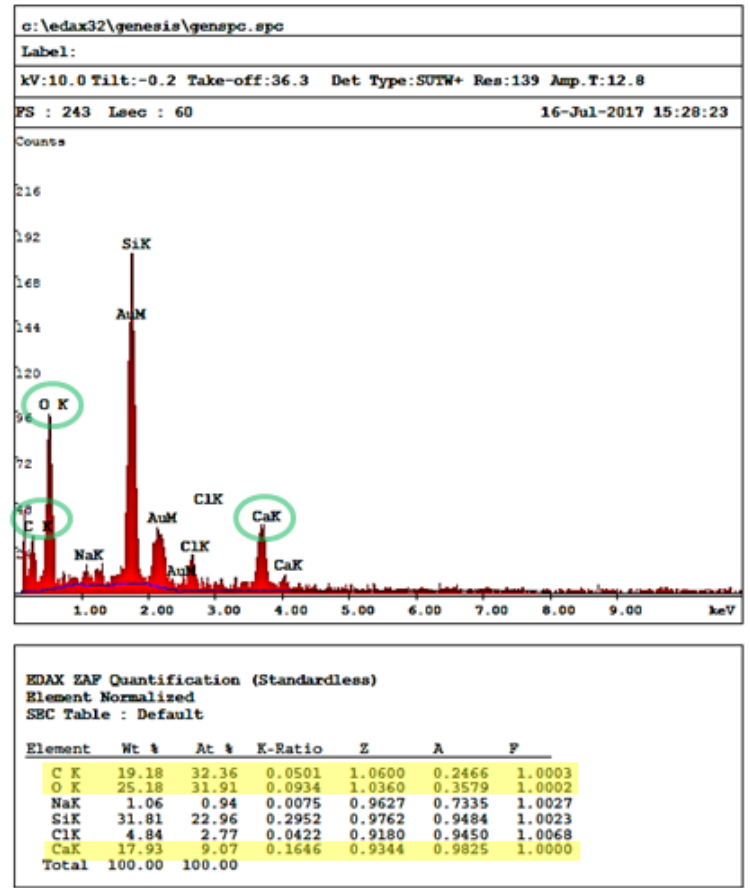

Figure 7. Result of Surface's Scanning EDAX test for Sample Inoculated Pseudomonas sp

\section{Conclusions and recommendations}

The experiment with the variation of bacterial content, concluded that in constant head permeability test and direct shear strength test, the best way to make a highest permeability reduction in inoculation 
method is inject $15 \%$ bacteria relative to total weight of soil. Highest permeability reduction in inoculation method is the bacteria inoculation method with 28 curing days with relative density $70 \%$ and giving the nutrient once a week, which the value of reduction $73,73 \%$ relative to the value of original sandy soil. Highest shear value increation in inoculation method is the bacteria inoculation method with 7 curing days with relative density $50 \%$ and the inoculation process done with cycle treatment, which the value of cohesion is 6,84 and the value of friction angle is $44,46^{\circ}$.

Based on California bearing ratio test result, at CBR result with 10 number of hits, the treatment soil can proved a significant penetration stress changed. From Scanning Electron Microscope test result of the inoculation sand test images, it can be seen extracellular polysaccharide formed attached to the sand wall which will fill the pore space between the sand soil particles and embed the particles. This proves that micro bacteria that are cultured or inoculated into sand samples can live, experience growth and development. In addition, it also seen on the wall of samples picture of began to form exopolysaccharide. The formed exopolysaccharide attached to the wall of the sand soil particles which will fill, patch, and close the pores between the sand soil particles.

There are some notes need to be more attention, as well as: the tools used to support the growth and development of micro bacteria inside the soil should be in a sterile state in order to minimize the growth of other organisms; need to review for the bubbling effect on soil pores and the swelling effect against the accuracy of the results; and due to the complexity, the applications of biological microorganism to geotechnical engineering would require an integration of microbiology, ecology, geochemistry, and geotechnical engineering knowledge.

\section{References}

1. W.G. Characklis and P.A. Wilderer, Glossary. In: Characklis, W. G., Wilderer, P. A. (eds) "Structure and Function of Biofilms," Wiley, Chichester, United Kingdom of Great Britain, pp. 369-371 (1989).

2. V. Ivanov and J. Chu, Environ Sci. Biotechnol, 7, 139-153 (2008)

3. A. Asyhari, M.R. Yunus, A.D. Haryani and M. Handayani, J. Appl. Technol. Environ. Sanitation, 4, 47-52 (2014)

4. PR. Chawla, IB. Bajaj, AS. Shrikant and RS. Singhal, Food Technol. Biotechnol, 47, 107-124 (2009)

5. J.T. DeJong, M.B. Fritzges and K. Nusslein, Journal of Geotechnical and Geoenviromental Engineering, 132(11), 1381-1392 (2006)

6. DJ. Tobler, MO. Cuthbert, RB. Greswell, MS. Riley, JC. Renshaw, SH. Sidhu and VR. Phoenix, Geochim Cosmochim Acta, 75, 3290-3301 (2011)

7. C. Qian, R. Wang, L. Cheng and J. Wang, Chin J Chem., 28, 847-857 (2010)

8. RH. Karol, Chemical Grouting and Soil Stabilization (New York (NY): Marcel Dekker, 558, 2003)

9. L.A. Van Paassen, C.M. Daza, M. Staal, D.Y. Sorokin, W. van der Zon and M.C. van Loosdrecht, Ecol Eng., 36, 168-175 (2010)

10. V.S. Whiffin, Microbial $\mathrm{CaCO} 3$ precipitation for the production of biocement (Doctoral dissertation, Murdoch University, 2004)

11. W. De Muynck, N. De Belie and W. Verstraete, Ecol Eng., 36, 118-136 (2010) 